\title{
O produtivismo acadêmico e seus impactos na pós- graduação stricto sensu: uma ameaça à solidariedade entre pares?
}

\author{
Academic productivity and its impacts in Postgraduate programs: is it a threat to solidarity \\ between peers?
}

Roberto Patrus $^{1}$

Douglas Cabral Dantas ${ }^{2}$

Helena Belintani Shigaki ${ }^{3}$

\begin{abstract}
Resumo
O produtivismo acadêmico, entendido neste ensaio como um fenômeno derivado dos processos de avaliação da pósgraduação, se caracteriza pela excessiva valorização da quantidade da produção acadêmica, tendendo a desconsiderar a sua qualidade. Já a solidariedade acadêmica é entendida aqui como um compromisso mútuo entre os pesquisadores, que voluntariamente dedicam-se à avaliação de produtos da atividade de um programa de pós-graduação. Entre essas atividades, escolhemos a avaliação de artigos por pares como "paradigma exemplar" da solidariedade acadêmica. Objetiva-se, com este texto, discutir os impactos do produtivismo na pós-graduação stricto sensu e avaliar o quanto o produtivismo ameaça a solidariedade acadêmica que o torna possível. A partir da distinção entre os conceitos de colaboração e solidariedade, forjados pelos autores, chama-se a atenção para o risco de o produtivismo corroer a noção de solidariedade acadêmica. Mesmo que isso ocorra, não haverá produtivismo sem colaboração, sem o trabalho silencioso e anônimo de um sem-número de avaliadores de periódicos que disponibilizam o seu tempo e sua expertise para avaliar os trabalhos de seus pares. Tal colaboração, entretanto, ocorreria de forma algo alienada, sem a noção de participação em uma comunidade de pesquisadores. Em suma, não pode existir produtivismo sem colaboração, embora possa haver produtivismo sem solidariedade.
\end{abstract}

Palavras-chave: Produtivismo acadêmico. Solidariedade acadêmica. Colaboração. Revisão por pares.

\begin{abstract}
Academic productivity, understood in this essay as a phenomenon derived from the evaluation processes of Postgraduation, is characterized by the excessive appreciation of the amount of academic production rather than its quality. Academic solidarity is understood here as a mutual commitment among researchers, who voluntarily dedicate their time to evaluate products of the activity of a Post-graduate program. Among these activities, we chose peer review as an
\end{abstract}

Agradecemos o apoio da Capes e da FAPEMIG, que colaboraram para a realização dessa pesquisa.

Artigo submetido em 23 de maio de 2013 e aceito para publicação em 10 de outubro de 2014.

DOI: http://dx.doi.org/10.1590/1679-39518866

1 Doutor em Filosofia pela Universidad Complutense de Madrid, com revalidação na UFRGS como Doutor em Administração; Professor adjunto IV da PUC Minas. Endereço: PPGA/PUC Minas - Avenida Itaú, 525, CEP 30535-012, Belo Horizonte - MG, Brasil. E-mail: robertopatrus@pucminas.br

2 Doutor em Administração pela PUC Minas; Professor da PUC Minas. Endereço: PPGA/PUC Minas - Avenida Itaú, 525, CEP 30535012, Belo Horizonte - MG, Brasil. E-mail: douglas.dantas@yahoo.com.br

3 Mestre em Administração pela PUC Minas. Endereço: PPGA/PUC Minas - Avenida Itaú, 525, CEP 30535-012, Belo Horizonte - MG, Brasil. E-mail: belintanihs@gmail.com 
"exemplary paradigm" of academic solidarity. This article aims to discuss the impacts of academic productivity in postgraduate programs and evaluate how it threatens academic solidarity that makes it possible. Based on the distinction between the concepts of collaboration and solidarity, made by the authors, the article alerts to the risk of academic solidarity be destroyed by academic productivity. Even if it happens, there will be no productivity without collaboration, without the silent and anonymous work of many and many reviewers that offer their time and expertise to evaluate their peers' papers. Such collaboration, however, would be alienated without the notion of participation in a community of researchers. In short, there is not productivity without collaboration, although productivity may exist without solidarity.

Keywords: Academic productivity. Academic solidarity. Collaboration. Peer review.

\section{Introdução}

O produtivismo acadêmico é entendido neste artigo como um fenômeno derivado dos processos de regulação e controle, em particular, os de avaliação, que se caracterizam pela excessiva valorização da quantidade de produção científico-acadêmica, tendendo a desconsiderar a sua qualidade (SGUISSARDI, 2010). Teve sua origem nos anos 1950 nos EUA e se tornou mundialmente conhecido pela expressão "public or perish", que significa que os professores/pesquisadores universitários que não publicassem de acordo com os parâmetros postos como ideais pelos órgãos financiadores, pela burocracia universitária ou pelo mercado, teriam sua carreira comprometida (FONSECA, 2001; NASCIMENTO, 2010; SGUISSARDI, 2010). O produtivismo acadêmico é decorrente do risco de que o produto final da pesquisa científica (a publicação) se transforme em um fim em si mesmo e não em um resultado decorrente do processo de produção de conhecimento.

No Brasil, esse fenômeno tem sido alvo de críticas que o associam direta ou indiretamente à implantação do atual modelo de avaliação da pós-graduação stricto sensu pela agência estatal de financiamento, regulação e controle, Capes, a partir dos anos 1996/1997. Foi nesse período que os critérios quantitativos da produção acadêmica foram intensificados como parâmetros para a classificação dos cursos de mestrado e doutorado em todas as áreas (SGUISSARDI, 2010). Nessa ocasião, houve uma mudança de paradigma de avaliação preconizada pela Capes: inicialmente concebida para aperfeiçoar a formação de professores, a avaliação passou a focar a formação de pesquisadores (MACHADO, 2007; ROSA, 2008).

Desde que foi feita a mudança decisiva na sistemática de relatórios (Coleta Capes, Currículo Lattes), aprimorados pelo avanço da informática desses últimos anos, que rotinas, normas, discussões e queixas se multiplicaram devido à pressão institucional por publicação (MATTOS, 2008). Os artigos publicados podem variar em uma escala de pontuação que contempla desde os periódicos internacionais indexados e de grande impacto na comunidade científica (em função do número de consultas e citações), até as publicações regionais de baixo impacto (MACHADO e BIANCHETTI, 2011; MOREIRA, HORTALE e HARTZ, 2004; NASCIMENTO, 2010).

Podemos considerar que a pressão por maior produtividade, a concorrência por mais verbas e a diminuição dos tempos para maturação de resultados são fatos constatados por todos aqueles imersos em programas de pós-graduação. Entretanto, a consideração de que a pressão por produtividade constitui-se em mecanismo de constrangimento coletivo por meio de instrumentos aparentemente objetivos e neutros (TREIN e RODRIGUES, 2010) é controversa. Existem posições antagônicas quando se trata de considerar o produtivismo e o sistema de pontos estabelecido pela Capes como critério de avaliação dos programas de pós-graduação e dos seus pesquisadores. Há os que são: (a) favoráveis ao sistema, sob o argumento de estimular a produção acadêmica e delimitar parâmetros objetivos para a sua avaliação; aqueles que (b) consideram o referido sistema como um grande equívoco da política educacional, pois corromperia o princípio da livre reflexão e pressionaria os pesquisadores a divulgar resultados preliminares ou até incompletos de sua pesquisa; e os que (c), em meio ao debate, assumem posição intermediária, que busca avaliar as virtudes e os vícios tanto do sistema quanto do indivíduo, dividindo entre eles as responsabilidades pelo produtivismo gerado a partir do modelo de avaliação. Dentre as três posições, cujos argumentos 
apresentamos nesse artigo, nenhuma aborda o tema da solidariedade acadêmica, lacuna que procuramos minimizar com este trabalho.

Solidariedade e cooperação acadêmicas podem ser compreendidas como um compromisso entre professores de pós-graduação que, voluntariamente, aceitam dedicar o seu tempo para a avaliação de produtos da atividade de um programa de pós-graduação. Entre essas atividades, podemos citar: a avaliação de artigos para periódicos; a participação em bancas examinadoras; a avaliação de projetos submetidos a agências de fomento; a avaliação de listas e revistas para compor o Qualis; a avaliação de programas de pós-graduação; a participação em editorias de revistas, coordenação, associações, colegiados de curso; e outras tantas que fazem parte do cotidiano de um professor universitário. Neste trabalho, elegemos a revisão por pares (peer review) como "paradigma exemplar" da solidariedade acadêmica, a partir de uma das categorias paradigmáticas propostas por Pena (2003).

Nosso propósito aqui é avaliar o quanto o produtivismo ameaça a solidariedade acadêmica que torna possível o primeiro. A partir da distinção entre o conceito de solidariedade forjado pelos autores e o de colaboração, chama-se a atenção para o risco de o produtivismo corroer a noção de solidariedade acadêmica. Para alcançar esse objetivo, procuramos, inicialmente, definir "produtivismo acadêmico", apresentado em íntima relação com o sistema de avaliação da Capes. Organizamos os argumentos favoráveis, contrários e conciliadores a partir de ampla revisão bibliográfica sobre o tema do produtivismo e sobre o sistema de avaliação da Capes. Não encontramos menção relevante aos temas da "cooperação" e da "solidariedade". Valendo-nos da revisão por pares como paradigma exemplar para tratar do tema da cooperação e da solidariedade, buscamos definir esses conceitos para, em seguida, responder ao nosso problema: o produtivismo acadêmico ameaça a solidariedade que o torna possível?

\section{Produtivismo acadêmico}

O produtivismo acadêmico, também conhecido como performatividade acadêmica, é uma ênfase exagerada na produção em grande quantidade de algo que possui pouca substância (ALCADIPANI, 2011). A valorização da quantidade seria demonstração de qualidade. Diferentes compreensões críticas desse fenômeno têm sido vastamente trabalhadas por pesquisadores brasileiros e estrangeiros, em particular, na Administração e na Educação, áreas nas quais trabalham os autores desse artigo (MATTOS, 2012; 2008; GODOI e XAVIER, 2012; HONIG e BEDI, 2012; MACHADO e BIANCHETTI, 2011; LEITE, KNIESS, RODRIGUES et al., 2011; FREITAS, 2011; ALCADIPANI, 2011; MASCARENHAS, ZAMBALDI e MORAES, 2011; SALO e HEIKKINEN, 2011; TREIN e RODRIGUES; 2011; MOREIRA, 2009; MELLO, CRUBELLATE e ROSSONI, 2009; ROSA, 2008). Cronologicamente, essa cultura começou a ser estudada recentemente, concentrando mais publicações a partir do ano de 2010. A adoção do produtivismo acadêmico no Brasil remete ao final dos anos 1970 e, de forma legitimada, aos anos 1990 (GODOI e XAVIER, 2012). A partir de 1988, algumas mudanças foram introduzidas no processo de avaliação da pós-graduação pela Capes, por conta da adoção de uma metodologia quantitativa, afetando, assim, o modo de conceber e organizar os programas no Brasil (ROSA, 2008; MOREIRA, 2009). Segundo Moreira (2009), a avaliação da Capes transforma o processo de conhecimento em mercadoria, limitando-o a produtos em níveis de desempenho e padrões de qualidade. Com frequência, a constante pressão por publicação atormenta os docentes da pós-graduação (GODOI e XAVIER, 2012; MOREIRA, 2009), contribuindo para que o desempenho dos professores seja medido pelo produto final (Moreira, 2009). Com isso, houve um grande salto na produção acadêmica em Administração, medido em termos de quantidade (BERTERO, CALDAS e WOOD, 1999). Atualmente, o termo produtivismo está associado a uma fábrica de fazer pontos (GODOI e XAVIER, 2012). Há quem diga que o produtivismo acadêmico, materializado em artigos, é também um "fetiche-conhecimento-mercadoria", contribuindo para o "mal-estar" da academia brasileira (TREIN e RODRIGUES, 2011), o qual é derivado dos processos de regulação, controle e gerenciamento, chamados de avaliação (SGUISSARDI, 2010; ROSA, 2008). 
O novo modelo de avaliação trouxe consigo uma série de consequências conhecidas: (a) intensificação do trabalho docente (BIANCHETTI e MACHADO, 2009; GODOI e XAVIER, 2012); (b) publicações requentadas ou maquiadas (KUENZER e MORAES, 2005); (c) prejuízo da saúde física e mental dos pesquisadores (BIANCHETTI e MACHADO, 2009;); (d) orientação tática do Programa para os critérios e indicadores que têm maior peso na avaliação da Capes; (e) dificuldade em encontrar professores dispostos a assumir cargos administrativos, orientar alunos ou participar de comitês da universidade (NASCIMENTO, 2010); (f) plágio e autoplágio (TREIN e RODRIGUES, 2011); (g) ênfase na dimensão mercantil do conhecimento (TREIN e RODRIGUES, 2011); (h) (de)formação na produção da nova geração de pesquisadores (GODOI e XAVIER, 2012); (i) fetiche da citação (MATTOS, 2012); (j) desonestidade nas publicações (RODRIGUES, 2007); (k) criação de um clima de terror nas IES (MOREIRA, 2009); (l) má qualidade nas publicações (MATTOS, 2008; MOREIRA, 2009; ALCADIPANI, 2011); (m) aumento de coautoria (LEITE, KNIESS, RODRIGUES et al., 2011); (n) criação da lógica do empilhamento (GODOI e XAVIER, 2012); e (o) "McDonaldização" das atividades docentes (ALCADIPANI, 2011; SALO e HEIKKINEN, 2011). Em meio a essa nova cultura, é comum encontrar professores voltados a produzir mais e mais (FREITAS, 2011).

Curiosamente, a não ser indiretamente sob a ótica da intensificação do trabalho docente (BIANCHETTI e MACHADO, 2009; GODOI e XAVIER, 2012), encontramos na literatura pesquisada raras menções ao trabalho solidário e voluntário que sustenta a avaliação e consequente produtividade do sistema de pósgraduação no Brasil. A crítica ao produtivismo acadêmico está geralmente associada à lógica industrial, própria do capitalismo moderno (ROSA, 2008). Assim como o "operário padrão", o professor modelo seria aquele que soma mais pontos a partir da sua publicação científica. Mesmo denunciando a sobrecarga de trabalho do professor, que além de dar aulas, pesquisar, orientar e publicar, recebe inúmeros pedidos de parecer de artigos e demais produtos acadêmicos, o tema da solidariedade como o lado oculto e não valorizado do produtivismo é uma lacuna teórica que justifica esse trabalho. Também entre os argumentos favoráveis ao produtivismo e ao sistema de avaliação da Capes, e para aqueles que adotam uma posição conciliadora o tema da solidariedade acadêmica, é mencionado apenas como adjetivo do trabalho constante de aperfeiçoamento da pós-graduação.

\section{Argumentos favoráveis ao produtivismo}

A análise de Macedo e Souza (2010), autoras que, na época, eram representantes da área de Educação junto à Capes e responsáveis pela condução do processo de avaliação dos programas no triênio 2007-2009, diverge da crítica de um predomínio de critérios quantitativistas no modelo de avaliação, embora compartilhem de algumas ressalvas à política de pós-graduação. Elas apresentaram uma radiografia baseada em dados oficiais do triênio 2004-2006, fornecidos pelos programas, a fim de dirimir a crítica de que a avaliação, tal como processada, tendia mais para o produtivismo do que para o equilíbrio em relação a outros quesitos. Segundo as autoras, essa crítica traduziria uma espécie de nostalgia, localizada nos idos de 1970, quando havia ampla maioria de manuais e adaptações de literatura estrangeira (MACEDO e SOUZA, 2010). Entre os seus argumentos, ponderaram que uma análise dos dados de produção dos programas gerados para a avaliação trienal 2004-2006 na área de Educação permitia questionar afirmativas como a de que existia produtivismo na área ou de que a produção docente tinha definido o resultado da avaliação dos programas. Afirmaram que outros indicadores estavam sendo considerados para compor o resultado da avaliação, o que desautorizaria a afirmar que a produção bibliográfica era a base do modelo que vinha sendo utilizado pela Capes.

Em defesa da pressão por produção acadêmica, também se coloca o argumento de Machado (2007, p. 140), segundo o qual "os incentivos, exigências e induções da Capes para instalar a cultura da pesquisa e das publicações, em um país sem muita tradição de práticas escritas, justifica-se e é nobre, pois é necessário que os trabalhos dos pesquisadores apareçam no espaço público". A razão para as exigências da Capes quanto à publicação pelos pesquisadores residiria nessa lógica básica do movimento da ciência e, nesse sentido, precisaria ser compreendida, aceita e praticada. Não seria suficiente, para o autor, obedecer às regras para obter resultados, de uma maneira instrumental e mecanicista, sem aprofundar o sentido das recomendações 
emitidas pelas autoridades oficiais, às quais se atribui um poder que, de fato, elas não têm (MACHADO, 2007). A Capes não estaria interessada em controlar os caminhos ou os processos adotados, mas, havendo pesquisa, esta teria que oferecer um resultado que aparecesse publicamente.

Devido aos altos investimentos envolvendo recursos públicos que não devem ser desperdiçados, espera-se que as pesquisas beneficiem a sociedade e a população. Isso significa que o controle aparentemente rígido e intolerante da Capes poderia ser interpretado como uma "luta contra o desperdício". Haveria um esforço para implementar critérios de avaliação que promovessem menos injustiça, tendo as comissões da Capes concluído que era menos discutível e menos perigoso avaliar os resultados em termos quantitativos do que aprovar ou reprovar um programa de pós-graduação utilizando critérios qualitativos; estes seriam mais suscetíveis às idiossincrasias, perspectivas e interesses das diferentes - e numerosas - comissões de avaliadores. O modelo atual de avaliação da pós-graduação seria o menos frágil que tem sido possível praticar, estando em constante aprimoramento, a partir da ação solidária, coletiva e cumulativa da comunidade, à semelhança da dinâmica de evolução do software livre (MACHADO, 2007). Esse último argumento aborda a ação solidária para o aperfeiçoamento do sistema, mas não a problematiza.

Em suma, os argumentos favoráveis às cobranças por publicação defendem o princípio de tornar público o resultado das pesquisas, lutar contra o desperdício de recursos públicos e induzir o desenvolvimento da pesquisa em níveis internacionais. A ausência de um modelo de avaliação provocaria maior prejuízo que eventuais efeitos colaterais produzidos pelo sistema. O produtivismo acadêmico é visto, nessa perspectiva, como um desses efeitos.

\section{Argumentos desfavoráveis}

O produtivismo acadêmico, no Brasil, alimenta-se do e no processo de competição entre universidades, programas de pós-graduação e entre docentes/pesquisadores engendrados por agências financiadoras de pósgraduação e pesquisa, seja pela Capes e seu modelo de avaliação, seja pelos mecanismos e normas adotados pelo $\mathrm{CNPq}$ e outras agências para concessão de auxílios à pesquisa e de bolsas. Para essas agências, o currículo Lattes é seu principal instrumento indicador de produtividade (NASCIMENTO, 2010; SGUISSARDI, 2010). Alguns editais de fomento à pesquisa exigem ou recomendam que o Programa do qual o candidato faça parte tenha conceito 5. Esses critérios são parâmetros para os concursos de acesso à (e progressão na) carreira acadêmica, para a obtenção de bolsas de estudo e de auxílios à pesquisa, e até, em muitos casos, para o próprio acesso a cargos administrativos (SGUISSARDI, 2010). Haveria, portanto, uma exagerada crença na "objetividade" do sistema de avaliação, como se toda pontuação atribuída aos canais de publicação (editoras, revistas e eventos) e, consequentemente, aos trabalhos publicados, não tivesse sido feita por agentes social e politicamente situados (ROSA, 2008).

Uma das críticas mais comuns é a de que a Capes adotou a política de valorização do "produto final", considerando as dificuldades para a avaliação do "processo". Assim, a qualidade do artigo científico será atestada pelos referees (avaliadores) do periódico ao qual foi submetido e a qualidade do periódico será indicada pelo seu fator de impacto (ALCADIPANI, 2011; LEITE, KNIESS, RODRIGUES et al., 2011; NASCIMENTO, 2010). A lógica do "publicar ou perecer" faz sentido para aquele indivíduo, instituição ou sistema que entende que ser "veloz" implica assumir a quantidade como medida de todas as coisas em prejuízo da qualidade, que adviria de uma reflexão amadurecida, exaustivamente discutida, logo, "menos veloz". O ritmo frenético do cotidiano do pesquisador, exigido a atuar simultaneamente em inúmeras frentes, vem impondo ao seu dia a dia uma lógica implacável e minimalista, em que tudo dura pouco e a interrupção é a regra, uma situação nada favorável para o trabalho cientifico sério, que exige paciência e recusa o imediatismo (MACHADO, 2007). Nessa dinâmica, o trabalho mais valioso é o mais recente e o acesso a esse de forma veloz se transforma em um diferencial para o sucesso de um pesquisador (CARVALHO e MANOEL, 2006). 
Para julgamento dos trabalhos desenvolvidos, há indicadores de desempenho que contribuem com a cultura da performatividade, coibindo a adoção de formas flexíveis e diferenciadas (MOREIRA, 2009), reduzindo a complexidade humana a números em uma tabela (MOREIRA, 2009). No entanto, do ponto de vista pragmático, o uso de indicadores auxilia na definição e avaliação de estratégias tecnológicas, bem como na orientação das atitudes e ações (GUIMARÃES e ALVES, 2010). Mattos (2008) argumenta que o uso de indicadores não diferencia a produção criativa da produção em escala. Deveria, portanto, haver uma análise de contexto e de conteúdo das citações e o real impacto do artigo no meio de atuação (CARVALHO e MANOEL, 2006).

As críticas que denunciam o produtivismo enxergam essa pressão institucional como um mecanismo de controle que visaria normalizar programas e pesquisadores à atual política de produção científica instalada no país, capturada e enredada na lógica do sistema capitalista e, como tal, reproduziria efeitos devastadores sobre a pós-graduação (MACHADO, 2007; ROSA, 2008). Em um contexto de economia global, compreendem essa aceleração como um desdobramento da Revolução Industrial e do cronômetro taylorista, traçando um paralelo entre o espaço de produção fabril e o espaço de produção científica, ambos voltados à maximização da produção, devidamente mensurados por indicadores que ajudam a controlar o fluxo, seja punindo os que não contribuem com os índices, seja recompensando os que adotam tempos e movimentos que alcancem a "melhor" forma de ampliar esses índices (ROSA, 2008). Nesse sistema, vale o que é lido, o que é citado; em outras palavras, o que tem mercado.

Contudo, apesar dos resultados apreciáveis que essa lógica gera, os resultados positivos quantificáveis viriam acompanhados de formas eficazes e criativas de impedir a realização plena do que exigem. Muitas dessas atividades seriam arranjos e acordos entre pares, indivíduos ou instituições, no intuito de fazer funcionar o sistema, movimentar recursos etc., não significando, necessariamente, pesquisas relevantes, com envolvimento e participação engajada, avaliações criteriosas e resultados com verdadeiro impacto social (MACHADO, 2007).

A adoção pela Capes de um sistema de indicadores de desempenho como ferramenta de gerenciamento dos índices de publicação, segundo Rosa (2008), levaria a deduzir que o modelo de quantificação adotado reflete a busca de resultados, cuja maximização define quem receberá os recursos. No contexto acadêmico, ocorreria uma espécie de benchmarking, gerido pela figura do fast researcher, que, em casos específicos, delegaria parte dos seus afazeres à sua equipe de produção, mestrandos e doutorandos devidamente selecionados em seus programas de pós-graduação (ROSA, 2008). Pode-se supor que a qualidade da educação superior ficaria comprometida por um modelo de avaliação que privilegia a formação do pesquisador, mensurando quantitativamente sua produção científica, em detrimento da formação integral do pós-graduando (SGUISSARDI, 2006).

Essa supervalorização da produção acadêmica tem gerado um descaso com a qualidade do que é produzido e isso é refletido na falta de compromisso com o avanço e aprofundamento do conhecimento (FREITAS, 2011). Tal fato pode ser observado na quantidade de publicações dos professores. Pesquisa a partir de dados documentais publicados pela Capes nos permitiram encontrar um professor da área de Administração que chegou a publicar 52 trabalhos no período de um ano, divididos em artigos de periódicos, anais de eventos e capítulos de livros (SHIGAKI e PATRUS, 2012). É certo que o próprio modelo de avaliação da Capes condiciona esse comportamento, no qual o conteúdo e sua relevância são tratados como meros detalhes, ao contrário da estrutura do artigo (FREITAS, 2011). No entanto, um único professor produzir 52 trabalhos em um ano, ou 4,3 por mês, é um dado que merece ser objeto de análise.

Igualmente, a demonstração da produtividade dos grupos de pesquisa, sobretudo em termos de publicação nos meios acadêmicos de melhor reputação nos respectivos campos, é um dos requisitos para a concessão de financiamentos de pesquisas e certos benefícios, tais como bolsa produtividade, melhores notas no ranqueamento da Pós-graduação, prestígio junto aos pares, participação em eventos acadêmicos nacionais e internacionais, dentre outros (TREIN e RODRIGUES, 2011; RODRIGUES, 2007; LEITE, KNIESS, RODRIGUES et al., 2011). Além disso, estima-se que a busca do melhor produto dentro do menor tempo 
possível com o processo estaria levando à seleção de alunos com alto potencial para publicação, o que pode vir a mudar o perfil dos alunos selecionados para os cursos de mestrado e doutorado (KUENZER e MORAIS, 2005; NASCIMENTO, 2010). Há o perigo de que os alunos socializados nesse sistema encarem a produção acadêmica como um fim em si mesmo, fazendo parte de uma geração que não pesquisa a fundo, mas apenas publica (ALCADIPANI, 2011). Insistir na existência de um conhecimento facilmente avaliado a partir de índices de publicação ou de impacto tornaria "invisíveis" os outros conhecimentos presentes (SPINK e ALVES, 2011).

Para Mattos (2008), autores de alta produtividade acreditam que quanto mais publicações com seu nome, maior a chance de conseguirem a autoqualificação, o prestígio e os benefícios tão almejados pelas IES. Mas eles não deixam de ter razão. Assim, eles continuam contribuindo com o ciclo anômalo que mantém o fenômeno produtivista pela caracterização do conhecimento científico (GODOI e XAVIER, 2012). Essa supervalorização da produtividade acadêmica, por sua vez, tem gerado descaso com a qualidade, ou rigor, do que se produz (FREITAS, 2011; MASCARENHAS, ZAMBALDI e MORAES, 2011), além de estresses e sofrimentos (LUIZ, 2006). No entanto, entre publicar ou perecer, alguns pesquisadores têm optado pela segunda alternativa (PATRUS e LIMA, 2012), renunciando ao trabalho em programas de pós-graduação.

Constata-se a multiplicação de textos oriundos de uma única investigação, a publicação de palestras transcritas e rapidamente revisadas, $\mathrm{o}$ abuso das coautorias, assim como a fronteira tênue entre autoria e falsa autoria, visando o aumento da produtividade (ALCADIPANI, 2011; KUENZER e MORAIS, 2005; MACHADO, 2007). Isso se refletiria na realização de eventos com centenas de exposições de trabalhos ditos científicos para auditórios vazios ou quase, o que não propicia nem seu debate nem sua efetiva divulgação, comprometendo a produção do conhecimento necessário ao desenvolvimento e soberania do país (SGUISSARDI, 2010; SPINK e ALVES, 2011). Desse modo, a corrida para "engordar o Lattes" e a luta desesperada por manter a sua inserção instalariam um verdadeiro "vale tudo", que manteria os pesquisadores produtivos, mas não raros, competitivos (FREITAS, 2011). Esse modus vivendi assumiria a característica de certo nomadismo, uma movimentação exacerbada que, ao mesmo tempo em que amplia horizontes e universaliza as concepções, tornaria dispersa a existência do pesquisador e praticamente impediria a compenetração necessária ao estudo e à reflexão aprofundada. Isso, de alguma forma, tornaria inócua boa parte de suas pesquisas, esgotando a sua finalidade nesse cômputo estatístico, terminando o ciclo das descobertas sem que elas incidam no campo social ou gerem algum benefício significativo (MACHADO, 2007).

Além disso, como adverte Lévy-Leblond (2011), uma concepção de conhecimento e de ciência hegemônica pode levar a uma ideologia cientificista e a equívocos no sistema de avaliação, que exige que a submissão aos padrões impostos pelos países centrais - capaz de delimitar desde o referencial teórico (em inglês, preferencialmente) até os temas mais relevantes a serem pesquisados - seja um requisito para uma pesquisa ocupar um lugar na "Big Science". Tal relação tem sido problematizada por uma perspectiva dita póscolonial, que busca repensar essa assimetria a partir da periferia como forma de resistência. A serviço dessa comunidade científica abstrata, estariam também os periódicos científicos, a partir de critérios exclusivos de qualidade e de excelência (RODRIGUES e REZENDE, 2010; SPINK e ALVES, 2011; WATERS, 2006).

Um argumento recorrente para aqueles que se posicionam contra o produtivismo acadêmico é o de que todo trabalho científico sério é demorado (ROSA, 2008). No Brasil, a impaciência estaria imperando sobre a disciplina e a reflexão na pesquisa; a coleta de dados com frequência seria assistemática; e a análise, abreviada (ROESCH, 2003; ROSA, 2008). O debate suscitado por estes críticos do produtivismo no Brasil parece estar em sintonia com o que, em âmbito internacional, foi denominado Slow Science, movimento lançado pelo antropólogo francês Joël Candau, na esteira do Slow Moviment, com aplicações em diversas áreas: Slow Food; Slow Travelling; Slow Living in Slow Cities; Slow Arts; e Slow Reading during Slow Education. Todos têm em comum a crítica a uma cultura (ocidental) da imediatez, da urgência, do tempo real e de projetos que se sucedem a um ritmo cada vez mais rápido (GUSDORF, 1995; CANDAU, 2011). No âmbito da ciência, o currículo Lattes do pesquisador estaria sendo cada vez mais avaliado pelo número de linhas escritas (publicações, comunicações e projetos), o que levaria à obsessão pela quantidade na produção 
científica e, consequentemente, deixaria de priorizar os saberes fundamentais a transmitir e a qualidade da atuação na gestão universitária (GOSSELAIN, 2011).

O Movimento Slow Science defende a necessidade de tempo com qualidade para se pesquisar, refletir, ler, escrever e ensinar, em prol da qualidade de vida do educador e da produção científica (CANDAU, 2011; GOSSELAIN, 2011; SALO e HEIKKINEN, 2011). Esse movimento prioriza alguns valores e princípios fundamentais: a) dedicação de metade do tempo à atividade de pesquisa, que continuaria a subsidiar o ensino; b) reivindicação do benefício de períodos regulares de pesquisa sem a sobrecarga do ensino ou gestão (um semestre a cada quatro anos, por exemplo); c) deixar de privilegiar a quantidade nos currículos, de modo que sejam avaliados em função de seu conteúdo, através de métodos e ferramentas apropriados; d) priorizar o ensino, melhorando as condições de trabalho do professor-pesquisador e diminuindo o tempo dedicado a atividades administrativas e; e) exigência do tempo necessário a atividades de gestão e estudo de documentos que lhe seriam submetidos. Privilegia-se, portanto, a qualidade, e não a quantidade na carreira acadêmica nas áreas de ensino, pesquisa e gestão (CANDAU, 2011; GOSSELAIN, 2011).

Diniz (2012c), em um editorial da RAE, Revista de Administração de Empresas, chamou a atenção para o fato de que os periódicos, na área de Administração, são, na maior parte dos casos, criados e mantidos por instituições de ensino e pesquisa mais com o objetivo de dar vazão à produção de seus pesquisadores e menos com o foco na produção de conhecimento de valor científico para toda a comunidade. Segundo o editor, esse fato suscitaria dois problemas: o formato dos periódicos dentro das instituições de ensino criaria departamentos, inviabilizando o desenvolvimento de um modelo próprio focado no negócio de publicações; e como esses departamentos seriam apenas centros de custos, gerenciados amadoristicamente através do trabalho dedicado e voluntário, não conseguiriam atingir um padrão de qualidade à altura do que se encontra em mercados editoriais mais profissionalizados. Ou seja, os periódicos que possuem melhor classificação seriam geralmente geridos por equipes de profissionais focados no "negócio" de publicação científica, ao passo que os periódicos de departamento ficariam em desvantagem em termos de valor científico, uma vez que seu impacto na comunidade acadêmica acabaria sendo menor (DINIZ, 2012c). Em outro editorial, Diniz (2012a) reforçou a denúncia contra os interesses comerciais de editoras científicas em detrimento de interesses acadêmicos, e alertou também para falhas em seus processos editoriais e para um viés que favoreceria "periódicos nativos de alguns poucos países". Enquanto não se buscar a competência de uma estrutura profissional, formada por equipe contratada e remunerada para isso, a qualidade de nossa produção estaria comprometida, defende o Editor (DINIZ, 2012b; 2012c).

A despeito do aumento do número de periódicos na área de Administração e a busca por aperfeiçoamento, e o aumento de periódicos especializados (BRITO, 2009), a pesquisa de Wood Jr. e Chueke (2008) também revelou, como lamentável e preocupante, o fenômeno da endogenia, segundo a qual periódicos científicos, de forma explícita ou discreta, adotavam uma política editorial de favorecimento dos pesquisadores-autores das suas instituições. Segundo a mesma pesquisa, duas razões sustentariam tal prática eticamente questionável: a proximidade física entre as redações dos periódicos e os pesquisadores da instituição a qual estão filiados; e a inércia em relação à situação anterior, quando pesquisadores submetiam artigos a periódicos da própria instituição (WOOD JR. e CHUEKE, 2008).

Contrariamente a essa prática, o Manual de Boas Práticas da Publicação Científica, da ANPAD (2010) destaca a importância do compartilhamento do processo editorial entre pesquisadores e docentes de diversas instituições, de modo a evitar que um autor e/ou editor vinculado à mesma instituição responsável pelo periódico tenha privilégios para publicação de seu artigo. Nesse caso, a porcentagem anual de artigos de autores vinculados ao periódico não deveria exceder $15 \%$ de sua publicação (ANPAD, 2010). De acordo com Mattos (2005), “... a independência de opinião, por mais incômoda que seja entre amigos ou 'partidários', pois, de certa forma, enfraquece ou desprestigia o grupo ou as relações, é um dos grandes recursos de desenvolvimento da academia, um dos pilares éticos de sua credibilidade" (MATTOS, 2005, p. 275). 
Em suma, o principal argumento contrário ao produtivismo aponta, por um lado, o uso de uma estratégia quantitativa para mensurar o trabalho na pós-graduação e, por outro, as consequências indesejáveis da busca da quantidade, em detrimento da qualidade.

\section{Argumentos conciliadores}

A partir de uma breve historiografia e com base no que preconiza a legislação brasileira para a educação, Cury (2010) afirma que o sistema de pós-graduação se constituiu como um sistema nacional com legislação pertinente a partir de uma decisiva atuação do Estado. Cury (2010) reconhece as virtudes do sistema, suas fragilidades e desafios por mais transparência e justiça no processo de avaliação da pós-graduação, particularmente quanto à avaliação da publicação acadêmica. Ele se pergunta quais os limites dessa necessária burocratização funcional para os administradores e como evitar o excesso nas tarefas de controle e de coordenação. É possível combinar a gestão burocrática, inerente à complexidade impessoal, eficiente para o sistema e tal princípio constitucional como o da gestão democrática e o da autonomia universitária? (CURY, 2010, p. 165)

A propósito da pressão institucional por publicação, Mattos (2008) afirma que a importância do trabalho realizado pelo sistema de avaliação dos cursos de pós-graduação pela Capes e da produção acadêmica gerada por eles é indubitável e que, sem negar que o sistema tem muito a melhorar no confronto com seus próprios fins, há que se repensar os limites e intenções de uma argumentação contra a pressão pela produção. Sua reflexão se ampara no fato de que a comunidade acadêmica no Brasil reconheceu que não podia participar do mundo da grande ciência sem se legitimar pelos padrões internacionais das universidades de ponta, daí o desenvolvimento de um inevitável e pretenso sistema objetivo de avaliação, que teria sua eficácia apoiada em três pontos: legitimação pelo julgamento por pares, indicados por sociedades acadêmicas; estabelecimento de um ranking entre programas, o que promoveria competição e rivalidade interna; e nivelamento da diversidade dos programas ao estruturar-se sob a ótica neutra do desempenho por números.

Essas formas de construir eficácia constituiriam um tipo de qualidade que definiria o sistema, a qualidade formal-instrumental, que mostraria grande competência. A qualidade formal poderia ser garantida sem o consenso sobre o sentido, a utilidade e a validade interna do que é dito. Isso aconteceria porque as qualidades formais são traduzíveis em quantidade e também uma boa argumentação, independentemente do conteúdo do trabalho (MATTOS, 2008).

A chamada síndrome do estresse acadêmico, para Mattos (2008), existe, mas o sistema de avaliação oficial não deveria ser culpado por isso. Segundo ele, o professor não deveria se obrigar a contabilizar mais do que o número mínimo anual de pontos (produção) definido por seu programa, atendendo também, em médias trienais, aos mínimos fixados pelo sistema de avaliação de que faz parte. Cumprir o mínimo exigido lhe permitiria trabalhar por seu projeto acadêmico pessoal e grupal. A cultura do "quanto mais publicar melhor", ao contrário, geraria hábitos de trabalho e institucionalizaria práticas de pesquisa peculiares e discutíveis, como a prevalência da metodologia associada à tecnologia (observância do script), base do padrão industrial na pesquisa (lógica fabril) sobre a epistemologia. O estudo competente de problemas sociais e humanos requer tempo e não deveria separar observação cuidadosa de criação criteriosa. $\mathrm{O}$ atual sistema de avaliação da Capes não teria como diferenciar a produção criativa da produção em escala.

Em trabalho mais recente, Mattos (2012) propõe a discussão sobre o produtivismo em outras bases. O autor nos adverte para o fato de que, com Capes ou sem Capes, o problema do produtivismo adquiriria novas proporções porque faria parte do trabalho sufocante da vida moderna em diversos setores e também de uma espiral de emulação interna na academia nacional e internacional. Falar em produtivismo deveria nos levar de um plano institucional e político à reflexão crítica sobre a falta de relevância do projeto de pesquisa dissimulada pela forma (MATTOS, 2012). 
Mas a que práticas de composição e legitimação institucional de trabalhos acadêmicos o autor estaria se referindo? Para ele, autores, avaliadores e leitores sabem do que se trata, ou suspeitam, ou têm experiência semelhante e entendem que, sem certos recursos acadêmicos, não se cumprem prazos, metas e, sobretudo, não se publica em veículos mais importantes e não se põe à altura da "concorrência", com currículos talvez similarmente enriquecidos. Um passeio pela estrutura do texto acadêmico investigado por Mattos (2012) apresenta uma lista de "estratégias de sobrevivência" que maximizariam a formalização e multiplicariam os textos de pesquisa, promovidas pelo pesquisador categorizado por ele como imaturo-produtivo: o recurso indevido aos apuds e às citações indiretas (tratadas como elemento formal), a variação do campo observado e a conservação do instrumento de análise, a primazia do método e do processamento de dados sobre o modelo teórico, o discurso vazio (auto-referenciado) e a falta de representação dos interesses do leitor (MATTOS, 2012).

Em suma, reconhecendo a importância da avaliação, sua feitura e gestão para dar visibilidade e melhor desempenho à pós-graduação de qualquer área, alguns autores ponderam fortalezas e fraquezas, como o gigantismo e a importância do modelo de avaliação da Capes, a despeito dos desafios que existem. Tais desafios seriam inerentes à opção epistemológica e política do modelo, e incentivam a tarefa de seu constante aperfeiçoamento.

\section{A solidariedade acadêmica e a revisão por pares como seu paradigma exemplar}

O conceito de solidariedade, ao longo do tempo, vem sendo empregado por diferentes áreas e em diferentes abordagens, como por exemplo, nas áreas de Sociologia, Economia, Saúde e Educação. Em sua origem, a solidariedade era um termo jurídico que designava a obrigação sobre os devedores quando cada um deles era tomado pelo todo (in solidum). Designa, também, dependência recíproca, na qual as características de alguém repercutem no outro. Há também a solidariedade como sentido unilateral, expressando a ideia de continuidade de gerações. E, por fim, a de dever moral (LALANDE, 1990; EWALD, 2003). Todas essas acepções diferem da que pretendemos utilizar neste artigo.

Recorrendo a Lalande e seu vocabulário técnico de filosofia, a solidariedade deve ser considerada por uma definição tripla: (a) advém de relações dadas ou concebidas; (b) de relações recíprocas; e (c) de relações inseparáveis (LALANDE, 1990). Com isso, ela não corresponderá a uma unidade isolada, nem a uma proporção entre duas ou mais unidades, mas à relação de todas as partes de um todo (COMPARATO, 2006). Aqui, temos um elemento que vai nos interessar na construção desse conceito: a sua ligação com a relação de todas as partes de um todo. Pode dizer-se que o termo solidariedade implica a compreensão de uma totalidade composta por partes que se relacionam. Guardemos esse elemento e continuemos a revisão do conceito na escassa literatura que procura defini-lo.

No campo da Sociologia, Durkheim (1999) identifica dois estados de coesão de uma sociedade por meio dos conceitos de solidariedade mecânica e solidariedade orgânica. A primeira ocorre quando os indivíduos compartilham de uma consciência coletiva comum, ou seja, o que de regra é aceita e conhecida por todos em uma sociedade homogênea, simples, sem divisão do trabalho, com indivíduos realizando atividades comuns. Já a solidariedade orgânica prevalece nas sociedades complexas, em que, tal como um organismo vivo, as partes dependem umas das outras para o bom funcionamento do todo. A divisão do trabalho presente nas sociedades modernas torna a solidariedade orgânica fundamental para a coesão social, segundo Durkheim (1999).

Observa-se na noção de solidariedade de Durkheim, sem considerarmos a distinção entre a mecânica e a orgânica (que dependem da divisão do trabalho), dois elementos fundamentais do conceito. O primeiro é o já reconhecido elemento de totalidade. Uma vez que as partes dependem umas das outras para o bom funcionamento do todo, pressupõe-se que a solidariedade implica o reconhecimento de uma totalidade da qual a parte que é solidária se sente partícipe de um todo maior. O segundo elemento é a coesão. A 
solidariedade promove coesão. Relacionando a coesão com a totalidade, partes solidárias promovem a coesão do todo do qual participam.

Outra forma de compreender a solidariedade é a partir do princípio da autogestão, no cooperativismo (WESTPHAL, 2008). E este pode ser um terceiro elemento fundamental ao conceito: a cooperação. Cooperar significa trabalhar juntamente com outro, co-laborar, contribuir com o trabalho de outro. Solidariedade implica, pois, cooperação.

Se pensarmos os três elementos até aqui destacados - totalidade, coesão e cooperação, podemos inferir que, embora a solidariedade implique cooperação com o todo, a cooperação não necessariamente implica solidariedade. Trabalhar junto é cooperar. Cooperar para tornar o todo coeso é solidariedade. A solidariedade exige compreender-se parte de um sistema, de um todo. Cooperar sem a noção do todo do qual se participa é apenas trabalhar junto, colaborar.

Tal distinção entre solidariedade e cooperação é enriquecida pela etimologia do termo solidariedade, oriunda do adjetivo solidus (sólido e consistente). Do adjetivo derivam o substantivo solum (fundamento e apoio) e também os verbos solidare (consolidar, segurar, fazer sólido) e solidescere (fazer-se sólido, consolidar-se). Assim, exercer a solidariedade implica fazer-se parte de algo maior, um todo, com vistas a solidificar, consolidar, tornar algo sólido, coeso. Entendemos, assim, a solidariedade como algo maior do que a cooperação ou colaboração entre pares, visto que a solidariedade, necessariamente, abrange a cooperação, mas a cooperação não abrange necessariamente a solidariedade.

Para fins da reflexão desenvolvida por esse artigo, compreende-se a solidariedade como um conjunto de relações cooperativas que visam consolidar uma totalidade, torná-la coesa, sólida. Estendendo o conceito para a solidariedade acadêmica, podemos falar em relações cooperativas no âmbito das universidades que promovem a coesão da academia, ou seja, a consolidação de uma rede de colaboração voluntária que dá sustentação ao fazer acadêmico. No âmbito acadêmico da pós-graduação, a solidariedade é fundamental para a realização de projetos e trabalhos de ensino e pesquisa. Professores e pesquisadores dedicam seu tempo e seus talentos para o intercâmbio com outras instituições de ensino e pesquisa, para avaliações de teses, dissertações, artigos de periódicos, projetos de pesquisa enviados a agências de fomento, seleção de professores a admitir, participação em associações de classe, órgãos do governo, agências de fomento, cooperação com entidades da sociedade civil ou do governo, atividades de extensão universitária e outras atividades comuns ao professor da pós-graduação.

No âmbito acadêmico, enfim, a solidariedade implica, principalmente, uma relação de interdependência entre pares. Consideramos a revisão por pares um "paradigma exemplar" (PENA, 2003) para tratar da solidariedade acadêmica. A revisão por pares é compreendida como um pedido de subvenção ou um papel a ser examinado por um terceiro (SMITH, 2006), especialista na mesma área (WARE, 2008). É o mecanismo de avaliação de desempenho mais utilizado no meio acadêmico (COUPÉ, 2010). A origem dessa atividade não é certa: alguns autores acreditam que sua origem está na censura do Estado, desenvolvida por meio do estabelecimento e prática apoiada na academia (FITZPATRICK, 2011); e outros a partir da Segunda Guerra Mundial, como resposta ao grande número de pesquisas científicas que surgiu naquele período.

Seja na abordagem cega, unilateral (single blind review) ou bilateral (double blind review), seja na abordagem aberta (open review), trata-se de uma atividade voluntária para professores pesquisadores, salvo os casos em que beneficiários de auxílios de agências de fomento assumem a contrapartida de avaliar trabalhos como consultores ad hoc. Mesmo assim, a atividade de revisão (de artigos ou projetos de pesquisa), embora fundamental no sistema de avaliação da pós-graduação, não é destacada nesse sistema. Trata-se de uma atividade-meio do mundo acadêmico, não de uma atividade-fim. Como o produtivismo enfatiza o produto, o fim, a atividade de avaliação, que é meio, tende a ser esquecida, lacuna sobre a qual procuramos refletir. 
Esse sistema de revisão por pares é, ao mesmo tempo, idolatrado e criticado. Sob o ponto de vista crítico, essa atividade não é, em grande parte, validada e, por conseguinte, seus efeitos são incertos (SMITH, 2006; WARE, 2008). Isso ocorre devido à subjetividade dos avaliadores, ainda que o processo de revisão não beneficie, diretamente, os avaliadores. No que tange à produção de conhecimento, a sobrecarga de trabalho dos editores e avaliadores pode ser compensada pelo retorno do seu trabalho para a academia: (a) melhoria da qualidade dos trabalhos publicados, (b) filtragem da produção de artigos e (c) selo de aprovação que o artigo satisfaz determinados padrões. Assim, os editores se beneficiam no apoio às suas decisões, do ponto de vista dos especialistas e os autores se beneficiam da assistência oferecida pelos revisores especialistas (WARE, 2008).

Considerando a revisão por pares como uma atividade essencial para a consolidação da pós-graduação, sua realização é potencialmente uma ação solidária, visto que contribui para a coesão acadêmica necessária a atividades de pós-graduação stricto sensu. Uma rede de colaboração solidária tende a beneficiar todos aqueles que a integram. Se um pesquisador encaminha um artigo para uma revista científica, seu trabalho será avaliado no mínimo por dois pares acadêmicos, sob a coordenação de um editor. Esse trabalho é voluntário, cooperativo. Ele será solidário na medida em que seus atores percebam a sua importância para a coesão do sistema, para a consolidação de uma rede de revisores e autores de diferentes periódicos que colaboram mutuamente.

Uma vez definido o conceito de solidariedade acadêmica e uma vez apresentada a revisão por pares como seu exemplo paradigmático, voltamos à pergunta que pretendemos discutir: o produtivismo acadêmico ameaça a solidariedade que o torna possível? Interessa-nos refletir sobre o eventual risco do produtivismo corroer as noções de pertinência a uma totalidade, de coesão e de cooperação que embasam o conceito de solidariedade aqui apresentado.

\section{O produtivismo acadêmico como ameaça à solidariedade entre pares}

O produtivismo é um fenômeno político. Desde a instituição da bolsa de produtividade do CNPq, que permitiu aumentar os salários dos professores mais produtivos das universidades federais sem ter de reajustar o salário de todos os professores, e da mudança paradigmática no modelo de avaliação da Capes, a compreensão sobre o fazer acadêmico da pós-graduação vem sofrendo transformações. O produtivismo revela uma opção política pelo gerencialismo, modelo marcado pela realização de metas, pela valorização da eficiência, pela avaliação do desempenho.

Curiosamente, quanto mais a publicação científica é valorizada e quanto mais o número de publicações passa a ter importância para a instituição e para o pesquisador, mais trabalho vai sendo exigido dos pesquisadores indicados para a avaliação dos manuscritos enviados para os periódicos. Há um sem número de pesquisadores a avaliar os artigos encaminhados para a revista. Para cada artigo publicado, pelo menos três colegas dedicaram seu tempo e seus talentos para avaliar o artigo. E para os muitos artigos recusados pelas revistas, outros tantos revisores e editores também se dedicaram voluntariamente. Aparentemente, o modelo parece sugerir que quanto mais publicamos, mais solidários tendemos a ser. Mas essa ideia não é assim tão linear. A fim de problematizar a questão, é importante reconhecer o caráter político do produtivismo e as tensões subjacentes ao processo de avaliação. Em seguida, relacionarmos o produtivismo com o conceito de solidariedade acadêmica.

O produtivismo acadêmico pressupõe a valorização do que pode ser mensurado em detrimento de produtos e resultados de natureza qualitativa, como, por exemplo, a formação da cidadania e da consciência crítica. Um artigo publicado em uma revista A1 tem um valor quantitativo determinado. Uma aula exemplarmente ministrada, que produz nos alunos a alegria interior de estarem no caminho de sua vocação profissional, não é tão fácil de ser mensurada. A máxima de que "o que não pode ser medido não pode ser avaliado" revela uma escolha epistemológica e política que pressupõe uma certa forma de ver o mundo. 
Diante das controvérsias presentes no processo de avaliação da pós-graduação, observam-se duas tensões contraditórias. De um lado, há os partidários de uma burocracia de caráter weberiano, impessoal, objetiva. De outro, aqueles que preferem um sistema de regulação que contemple avaliações de natureza qualitativa, visitas de comissões in loco e a relativização de indicadores quando o seu uso parece distorcer a realidade. Aqueles que defendem um sistema impessoal preferem estabelecer métricas cujo uso permitiria uma avaliação objetiva. Aqueles que consideram essa abordagem um reducionismo diante do propósito de formação da pós-graduação, tendem a criticar e se opor ao produtivismo acadêmico e ao modelo de avaliação vigente.

Se, por um lado, a regulação de natureza burocrática e impessoal pode levar a distorções de avaliação em função de, por exemplo, relatórios ou formulários mal preenchidos, de outro, avaliações de natureza qualitativa podem levar ao clientelismo, em que demandas com maior poder de influência tendem a ser atendidas. Nesse caso, jogos de interesse podem enviesar a avaliação. Como se pode perceber, temos procurado relacionar o produtivismo acadêmico com o processo de avaliação da pós-graduação. Ora, o produtivismo, como vem sendo pontuado nesse artigo, está intimamente relacionado com a avaliação. Institucionalmente, o Programa bem avaliado goza de prestígio e reputação. Individualmente, o pesquisador produtivo também ganha prestígio e se habilita a conquistar bolsas e ter seus projetos aprovados pelas agências de fomento.

De fato, a cultura de produtivismo, instituída com a influência dos procedimentos avaliativos da Capes aos programas de mestrado e doutorado, auxilia na alteração dos significados da academia e na produção de novos perfis acadêmicos (ROSA, 2008; MOREIRA, 2009). Recuperando a tônica do que foram as duas posições pró e contra a pressão por publicação, identificamos uma convergência no fato de que ambas reconhecem os méritos e avanços que a pós-graduação no Brasil alcançou com esse modelo. No entanto, os defensores da pressão por publicação entendem o produtivismo como "desvio de função" do pesquisador, não se devendo "perder de vista que a própria dinâmica do sistema é um resultado das nossas práticas, que se relacionam aos acordos intersubjetivos, negociados e atualizados no cotidiano" (ROSA, 2008, p. 108). Nesse caso, não haveria a substituição do atual modelo de avaliação da Capes por outro que não seja regulador e quantitativista, propondo, quando muito, a inclusão de critérios mais qualitativos e uma atenção maior ao processo.

Os mais críticos, por sua vez, entendem que estamos diante de uma consequência direta e inevitável do modelo de regulação e fomento da pós-graduação, o que sinalizaria a necessidade de se rever a lógica do modelo Capes de avaliação e a pretensa objetividade que ele quer garantir, particularmente, no que se refere ao processo de avaliação da produção acadêmica. Entretanto, não parece haver alternativa no horizonte das discussões acadêmicas para o modelo em voga. Sua retirada pura e simples daria lugar a avaliações subjetivas, terreno fértil para o clientelismo presente na cultura brasileira.

Considerando as posições favoráveis, contrárias e conciliadoras ao produtivismo, o mais razoável a conjecturar é que as regras do jogo não serão mudadas no curto prazo. Contribui para essa avaliação o poder econômico e a enorme influência de grandes redes editoriais capazes de convencer um pesquisador a submeter e ceder os direitos autorais do seu trabalho a um "Journal" de alto fator de impacto e não ter acesso gratuito ao artigo que ele próprio escreveu. Redes editoriais abertas, de acesso livre, como as que temos no Brasil são riquezas que os estrangeiros admiram, visto permitir que o conhecimento produzido nas universidades, muitas vezes patrocinadas por dinheiro público, seja compartilhado por todos aqueles que o desejam.

Nessa perspectiva, uma alternativa seria pontuar, no sistema de avaliação da pós-graduação, as atividadesmeio, entre elas, a revisão de artigos para periódicos, como sugere Rosa (2008) ao propor a redistribuição da pontuação das atividades dos professores. Tal medida, aparentemente adequada, poderia ser concebida como uma mercantilização da solidariedade que sustenta a lógica do sistema de produção vigente. Analogamente à pergunta de Sandel (2012) - "o que o dinheiro não compra?" -, a pontuação pelas atividades-meio poderia gerar a pergunta: “o que 'os pontos da Capes' não compram?” A atividade potencialmente solidária 
assumiria um caráter instrumental, perdendo o seu caráter de consolidação de um sistema. Ela ficaria reduzida a mera cooperação, trabalho colaborativo, sem a dimensão de pertinência a uma totalidade que o termo solidariedade evoca e que assumimos como fundamental ao conceito.

Perder a dimensão da solidariedade acadêmica é uma ameaça já presente em meio à cultura do produtivismo. Ter um artigo recusado por uma revista e encaminhá-lo para outra sem levar em consideração sequer uma linha dos pareceres elaborados pelos revisores revela a ausência da noção de totalidade, a falta de consciência de uma rede de colaboração que precisa de coesão para fortalecer a produção científica da área. Não é raro que editores condicionem o recebimento de um artigo ao cadastramento do autor como avaliador, se adequadamente qualificado. Essa exigência revela que todos querem ter seu artigo publicado, mas nem todos querem se dar ao trabalho de avaliar para que outros também tenham seus artigos publicados. Nascimento (2010) já alertava para o risco da perda de prestígio de atividades que não contabilizem pontos, como a gestão de programas, a avaliação de artigos, a participação em bancas. Se posso dispor do meu tempo para pesquisar, escrever e encaminhar para a publicação, por que vou gastá-lo com atividades que tomam meu tempo e me afastam das metas pelas quais sou avaliado? Ora, raciocínios como esse ameaçam o sistema como um todo, porque só existe produção científica porque há um sem número de avaliadores que doam seu tempo, energia e expertise para avaliar o manuscrito.

Sem a dimensão de solidariedade, o "publicar ou perecer" pode transformar-se em publicar e perecer. Tal perecimento não seria do indivíduo autor, mas do sistema em si. A solidariedade se converteria em mera colaboração utilitária, tendo em vista o curto prazo e com uma perspectiva individual, pragmática, em prejuízo de uma perspectiva comunitária, sistêmica e de longo prazo.

\section{Considerações finais}

Nesse artigo, procuramos construir o conceito de solidariedade acadêmica. Para isso, revimos a escassa literatura sobre o tema solidariedade que, embora apareça com frequência na literatura, raramente é definido. Essa lacuna exigiu reconhecer nas definições encontradas os elementos constitutivos do conceito. Tais elementos são a totalidade, a coesão entre as partes e a cooperação. Assim, a solidariedade foi definida como um conjunto de relações cooperativas que visam consolidar uma totalidade, torná-la coesa, sólida. De posse do conceito de solidariedade, entendemos a solidariedade acadêmica como um conjunto de relações cooperativas no âmbito das universidades que promovem a coesão da academia, ou seja, a consolidação de uma rede de colaboração voluntária que dá sustentação ao fazer acadêmico. Ao definir solidariedade, apontamos que a cooperação é um de seus elementos, mas distinguimos um conceito do outro. A solidariedade contempla a cooperação, mas a cooperação não necessariamente é solidária, podendo ser de caráter pragmático, utilitarista. Nessa perspectiva, a cooperação que existe na solidariedade tem um caráter, no mínimo, comunitário, uma vez que reconhece a pertinência a uma totalidade da qual faz parte. Tais definições podem ser consideradas uma pequena contribuição desse artigo.

Diante do contexto de produtivismo na academia, procuramos problematizar o quanto ele ameaça a solidariedade acadêmica. A resposta a essa pergunta é positiva. O produtivismo ameaça a solidariedade entre pares do sistema de pós-graduação na medida em que tende a corroer a noção de pertinência a esse sistema, prejudicando a consciência da necessidade de coesão e de cooperação entre pares. Com tal alerta, pretende-se uma contribuição à discussão sobre o produtivismo, uma vez que o tema da solidariedade ainda não tinha sido contemplado nesse debate.

À guisa de conclusão, resta pensar algumas alternativas para o problema do produtivismo e sua relação com o modelo de avaliação. A primeira alternativa é de caráter individual e pode ser levada a cabo pelo pesquisador por meio do cumprimento das exigências da avaliação da Capes sem levá-las ao absurdo, a fim de desenvolver um projeto de pós-graduação autônomo, que persiga metas próprias com vista à produção de conhecimento. Assim, "o compromisso maior da pesquisa deveria ser produzir e elevar conhecimentos para a melhoria da vida individual e coletiva em suas múltiplas dimensões e interfaces" (FREITAS, 2011, p. 1160). 
Cabe a cada pesquisador ter um projeto compartilhado com seu Programa de pós-graduação e avaliar se ele se reduz de fato a publicar, publicar e publicar. Ele pode cumprir as exigências da avaliação da Capes sem exagero, de modo a cumprir as metas e ter o aval para desenvolver um projeto de Pós graduação autônomo. Tal alternativa parece possível e conciliadora. Como diria o ex-presidente do Banco Real, Fábio Barbosa, "resultado é o que resulta" (TANURE e PATRUS, 2011, p. 39). Um bom projeto pedagógico e estratégico para a condução da pós-graduação, sem dúvida, promoverá os resultados esperados se for bem conduzido. As pesquisas promoveriam o conhecimento e a aplicação desse conhecimento, com as respectivas publicações.

A segunda alternativa é pensar o corpo docente permanente de um Programa como um grupo e não como a soma de desempenhos individuais. Em outras palavras, trata-se de um "corpo", unificado por um projeto, mas com membros diferentes. Parafraseando São Paulo, que disse que "assim como o corpo é um, e tem muitos membros, e todos os membros do corpo, embora muitos, formam um só corpo" (1 Coríntios, 12:12), o corpo docente de um Programa pode ter professores com competências diferentes, considerando a docência, a gestão dos programas, a pesquisa e, por conta dos mestrados profissionais, a articulação com empresas, organizações públicas e da sociedade civil. Hoje, as métricas do sistema de avaliação são individualizadas no tocante à produção dos professores. Avalia-se, também, a distribuição, exigindo-se que uma porcentagem determinada dos professores tenha produção científica e produção técnica. Tal avaliação não é a avaliação do corpo docente. É a avaliação dos membros do corpo docente.

Propõe-se que o corpo docente permanente seja avaliado como corpo. Isso só é possível se ele for pensado como permanente, isto é, constante, coeso, consolidado. As metas devem ser aquelas do Programa como um todo e não a soma de metas individuais de seus membros. Tais metas podem contemplar o talento e o tempo do professor dedicado a atividades de gestão, de editoria, de estabelecimento de convênios. Pensar o corpo docente permanente como uma totalidade, que exige que seus membros colaborem entre si para a consolidação de um projeto de mestrado e ou de doutorado é pensar a solidariedade no âmbito de um microssistema de um Programa de pós-graduação. Cooperar, sabendo-se parte do sistema, colaborando para torná-lo sólido, consolidá-lo, é exercer a solidariedade. Ela pode ser exercida no âmbito do sistema da pósgraduação stricto sensu, como por exemplo, a partir da revisão por pares. E pode ser exercida, também, no âmbito do próprio Programa de pós-graduação, uma totalidade menor.

Enfim, não existe produtivismo acadêmico sem cooperação acadêmica. Toda moeda tem dois lados. A do produtivismo pode ter o verso da cooperação ou o da solidariedade. Vai depender da consciência dos pesquisadores, de que fazem parte de um sistema cujas partes são interdependentes. E pode melhorar muito se a avaliação da Capes analisar o corpo (docente permanente) e não a soma dos seus membros.

\section{Referências}

ALCADIPANI, R. Academia e a fábrica de sardinhas. Organizações \& Sociedade, Salvador, v. 18, n. 57, p. 345-348, 2011.

ASSOCIAÇÃO NACIONAL DE PÓS-GRADUAÇÃO E PESQUISA EM ADMINISTRAÇÃO. Boas práticas da publicação científica: um manual para autores, revisores, editores e integrantes de corpos editoriais. Disponível em <http://www.anpad. org.br/diversos/boas_praticas.pdf. 2010>. Acesso em: 22/06/2014

BERTERO, C. O. Editorial. Revista de Administração de Empresas-eletrônica, v. 6, n. 1, 2007.

BERTERO, C. O.; CALDAS, M. P.; WOOD JR., T. Produção científica em administração de empresas: provocações, insinuações e contribuições para um debate local. Revista de Administração Contemporânea, v. 3, n. 1, p. 147-178, 1999.

BIANCHETTI, L.; SGUISSARDI, V. Dilemas da pós-graduação: gestão e avaliação. Autores Associados. 2009. 
BÍBLIA. Português. Bíblia sagrada. Tradução de Padre Antônio Pereira de Figueredo. Rio de Janeiro: Enciclopédia Britannica, 1980. Edição Ecumênica.

BRITO, E. P. Z. Editorial. Revista Angrad, v. 10, n. 2, 2009.

BURRELL, G.; MORGAN, G. Sociological paradigms and organizational analysis: elements of the sociology of corporate life. Burlington: Ashgate Publishing, 1992.

CALDAS, M. Paradigmas em estudos organizacionais: uma introdução à série. Revista de Administração de Empresas, v. 45, n. 1, p. 53-57, 2005.

CANDAU, J. Pour um mouvement Slow Science: 17 juillet 2011. Disponível em <http //slowscience.fr>. Acesso em:

CARVALHO, Y.; MANOEL, E. J. Para além dos indicadores de avaliação da produção intelectual na grande área da saúde, Movimento, v. 12, n. 3, p. 193-225, 2006.

COMPARATO, F. K. Ética: direito, moral e religião no mundo moderno. São Paulo: Companhia das letras, 2006.

COUPE, T. Peer review versus citations - an analysis of best paper prizes. Kyiv School of Economics, 2010.

CURY, C. R. J. O debate sobre a pesquisa e a avaliação da pós-graduação em educação. Revista Brasileira de Educação, v. 15, n. 43, p. 163-165, 2010.

DINIZ, E. Editorial. Revista de Administração de Empresas, v. 52, n. 4, 2012 a.

DINIZ, E. Editorial. Revista de Administração de Empresas, v. 52, n. 5, 2012b.

DINIZ, E. Editorial. Revista de Administração de Empresas, v. 52, n. 6, 2012c.

DURKHEIM, É. Da divisão do trabalho social. São Paulo: Martins Fontes, 1999.

EWALD, F. Solidariedade. In: CANTO-SPERBER, M. (Org.). Dicionário de Ética e Filosofia Moral. Trad. de Ana Maria Ribeiro-Althoff et al. São Leopoldo: Unisinos, 2003.

FITZPATRICK, K. Planned Obsolescence: publishing, technology, and the future of the academy. Nova York: NYU Press Short. Kindle Edition, 2011.

FEDERAÇÃO DE AMPARO À PESQUISA DO ESTADO DE SÃO PAULO. Pesquisadores no Brasil publicam 56\% dos artigos científicos originados na América Latina. 3. Disponível em: <http://www.fapesp.br/indicadores/boletim3.pdf>. Acessado em: março de 2011.

FONSECA, C. Avaliação dos programas de pós-graduação: do ponto de vista de um nativo. Horizontes Antropológicos, v. 7, n. 16, p. 261-275, 2001.

FREITAS, M. O pesquisador hoje: entre o artesanato intelectual e a produção em série. Cadernos EBAPE.BR, v. 9, n. 4, p. 1158-1163, 2011

FROTA, G. B. Estratégias de professores frente ao sofrimento no trabalho: um estudo em uma IES no estado de Minas Gerais. 142 f. (Dissertação Mestrado). Puc Minas, 2012.

GODOI, C.; XAVIER, W. O produtivismo e suas anomalias. Cadernos EBAPE.BR, v. 10, n. 2, p. 456-465, 2012.

GOSSELAIN, O. P. Slow Science, la désexcellence. Uzance, n. 1, p. 129-140, 2011. Disponível em: <http://www.cdsauwb.be/www.cds-auwb.be/uploads/file_/Slow\%20Science.pdf>. Acesso em: 22/06/2014.

GUIMARÃES, J. A.; Alves, I. T. G. Dez anos do portal de periódicos da Capes: histórico, evolução e utilização, RBPG, v. 7, n. 13, p. 218-246, 2010.

GUSDORF, G. Professores para quê? 2. ed. São Paulo: Martins Fontes, 1995. 
HONIG, B.; BEDI, A. The fox in the hen house: a critical examination of plagiarism among members of the academy of management. Academy of Management Learning \& Education, v. 11, n. 1, p. 101-123, 2012.

KIRSHBAUM, C.; PORTO, E. C.; FERREIRA, F. C. M. Neo-Institucionalização na produção acadêmica em Administração, RAE, v. 3, n. 1, p. 1-16, 2004.

KUENZER, A. Z.; Morais, M. C. M. Temas e tramas na pós-graduação em educação. Educação e Sociedade, v. 26, n. 93, p. 1341-1362, 2005.

LALANDE, A. Vocabulário técnico e crítico da filosofia. 3. ed. São Paulo: Martins Fontes, 1990.

LEITE, N. R. P. et al. A. A ética na produção, orientação, submissão, avaliação e publicação científica: quem assume a responsabilidade? Artigo apresentado no Encontro de Ensino e Pesquisa em Administração e Contabilidade, João Pessoa, PB: Brasil, 3, 2011.

LEVY-LEBLOND, J. Notes pour une nouvelle politique scientifique. Disponível em: $<$ www.tribunes.com/tribune/alliage/61/page3/page3.html>. Acesso em 10 de março de 2012.

LUIZ, R. R. Avaliação de produtividade acadêmica: uma proposta de quantificação, RBPG, v. 3, n. 6, p. 300-312, 2006.

MACEDO, E.; SOUZA, C. P de. A pesquisa em educação no Brasil. Revista Brasileira de Educação, v. 15, n. 43, p. 166-176, 2010.

MACHADO, A. M. N. Políticas que impedem o que exigem: dimensões controvertidas na avaliação da pós-graduação brasileira. Universidade e Sociedade, v. 39, p. 137-149, 2007.

MACHADO, A.; BIANCHETTI, L. (Des)fetichização do produtivismo acadêmico: desafios para o trabalhadorpesquisador. Revista de Administração de Empresas, v. 5, n. 3, p. 244-254, 2011.

MASCARENHAS, A.; ZAMBALDI, F.; MORAES, E. Rigor, relevância e desafios da academia em administração: tensões entre pesquisa e formação profissional. Revista de Administração de Empresas, v. 51, n. 3, p. $265-279$, 2011.

MATTOS, P. L. C. L. de. Sobre a ética do pesquisador: uma dimensão pouco explorada. Gestão. Org, v. 3, n. 3, p. $274-$ 280,2005

MATTOS, P. L. C. L. de. Nós e os índices - a propósito da pressão institucional por publicação. Revista de Administração de Empresas, v. 48, n. 2, p. 144-149, 2008.

MATTOS, P. L. C. L. de. Pés de barro do texto "produtivista" na academia. Revista de Administração de Empresas, v. 52, n. 5, p. 566-573, 2012.

MELLO, C.; CRUBELLATE, J.; ROSSONI, L. Redes de coautorias entre professores de programas brasileiros de pósgraduação (stricto sensu) em administração: aspectos estruturais e dinâmica de relacionamento. Revista de Administração Mackenzie, v. 10, n. 5, p. 130-153, 2009.

MOREIRA, A. F. A. A Cultura da performatividade e a avaliação da Pós-Graduação em Educação no Brasil, Educação em Revista, v. 25, n. 3, p. 23-42, 2009.

MOREIRA, C. O. F.; HORTALE, V. A.; HARTZ, Z. A. Avaliação da pós-graduação: buscando consenso. Revista Brasileira de Pós-Graduação, v. 1, n. 1, p. 26-40, 2004.

NASCIMENTO, L. F. Modelo Capes de avaliação: quais as consequências para o triênio 2010-2012? Administração: Ensino e Pesquisa, v. 4, n. 11, p. 579-600, 2010.

NOGUEIRA, M. A. Organizações complexas e sociedade da informação. O "sofrimento" como metáfora organizacional. Organizações \& Sociedade, v. 10, n. 28, p. 145-162, 2003.

PATRUS, R.; LIMA, M. Entre a Formação de Professores e de Pesquisadores nos Programas de Pós-graduação Stricto sensu em Administração: Contradições e Alternativas. Anais do XXXVI EnANPAD. Rio de Janeiro: Brasil, 2012. 
PENA, R. P. M. A ciência como jogo: e outros ensaios sobre ética e filosofia da ciência. FACE-FUMEC. 2003.

RODRIGUES, L. O. C. Publicar mais, ou melhor? O Tamanduá Olímpico, Revista Brasileira de Ciência e Esporte, v. 29, n. 1, p. 35-48, 2007.

RODRIGUES, S. B. Comentando: 'Quem responde pelo desempenho limitado da produção científica em Administração no Brasil?’ Organizações \& Sociedade, v. 11, n. 29, p. 193-196, 2004.

RODRIGUES, S. B.; REZENDE, N. A. O tamanduá olímpico a caminho da obesidade científica. Revista Médica de Minas Gerais, v. 20, n. 3, p. 375-379, 2010.

ROESCH, S. M. A. Quem responde pelo desempenho limitado da produção científica em Administração no Brasil? Organizações \& Sociedade, v. 10, n. 28, p. 165-167, 2003.

ROSA, A. "Nós e os índices" - um outro olhar sobre a pressão institucional por publicação. Revista de Administração de Empresas, v. 48, n. 4, p. 108-114, 2008.

SALO, P.; HEIKKINEN, H. Slow science: an alternative to macdonaldization of the academic lifestyle, 2011. Disponível em <http://slowscience.fr/wp-content/uploads/2011/07/Slow-Science-English-2011.pdf >. Acesso em 10 de março de 2012.

SANDEL, M. O que o dinheiro não compra: os limites morais do mercado. Civilização Brasileira. 2012.

SANTOS, L. Formação de professores na cultura do desempenho. Educação \& Sociedade, v. 25, p. 1145-1157, 2004.

SHIGAKI, H. B.; PATRUS, R. O papel da produção intelectual no sistema de avaliação dos programas de Administração pela Capes. Teoria e Prática em Administração (TPA), v. 2, n. 2, p. 126-150, 2012.

SGUISSARDI, V. A avaliação defensiva no "modelo CAPES de avaliação" - É possível conciliar avaliação educativa com processos de regulação e controle do Estado? Perspectiva, v. 24, n. 1, p. 49-88, 2006.

SGUISSARDI, V. Produtivismo acadêmico. In: Oliveira, D. A.; Duarte, A.; Vieira, L. (Org.). Dicionário de Trabalho, Profissão e Condição Docente. Belo Horizonte, MG: Faculdade de Educação/UFMG, 2010. 22 p.

SMITH, R. Peer review: a flawed process at the heart of science and journals. Journal of the royal society of medicine, v. 99, n. 4, p. 178-182, 2006.

SPINK, P. K.; ALVES, M. A. O campo turbulento da produção acadêmica e a importância da rebeldia competente. Organizações \& Sociedade, v. 18, n. 57, p. 337-343, 2011.

TANURE, B.; PATRUS, R. Os dois lados da moeda em fusões e aquisições. Rio de Janeiro, Elsevier, 2011.

TREIN, E.; RODRIGUES, J. O mal-estar na academia: produtivismo científico, o fetichismo do conhecimento mercadoria. Revista Brasileira de Educação, v. 16, n. 48, p. 769-819, 2010.

WARE, M. Peer review: benefits, perceptions and alternatives. Publishing research consortiu, 2008. 1-20 p.

WATERS, L. Inimigos da esperança: publicar, perecer e o eclipse da erudição. 1. ed. São Paulo: UNESP, 2006.

WESTPHAL, V. H. Diferentes matizes da ideia de solidariedade. Revista Katálysis de Florianópolis, v. 11, n. 1, p. 43-52, 2008.

WOOD Jr., T.; CHUEKE, G. V. Ranking de produção científica em Administração de Empresas no Brasil. Revista de Administração Mackenzie, v. 9, n. 4, p. 13-31, 2008. 